\title{
HERPES ZOSTER OPHTHALMICUS IN AN 8-YEAR-OLD CHILD*
}

\author{
BY \\ DOREEN A. BIRKS \\ Royal Eye Hospital, London
}

HERPES zoster ophthalmicus is unusual in the young and few cases have been reported (Duke-Elder, 1938; Edgerton, 1945). A proportion of these are thought to be symptomatic rather than epidemic in type. The following case of the epidemic type occurred in a young girl, keratitis being the sole complication.

\section{Case Report}

A girl aged 8 years had noticed pain over the left side of the forehead 4 days before admission to hospital on July 18, 1960. The following day a rash had appeared over the left side of the forehead and the left eye became painful. There was no history of trauma or recent infection, but there had recently been several cases of chickenpox at her school, and the child herself had not had chickenpox previously.

Examination.-The visual acuity in the right eye was $6 / 5$ and the eye appeared normal. In the left eye the visual acuity was $6 / 18$, and there was a vesicular rash along the distribution of the first division of the left $\mathrm{V}$ cranial nerve (Figure). Hutchinson's sign, photophobia, lacrimation, and miosis were present. Corneal sensation was depressed. The slit lamp showed no flare or cells. There was no corneal staining.

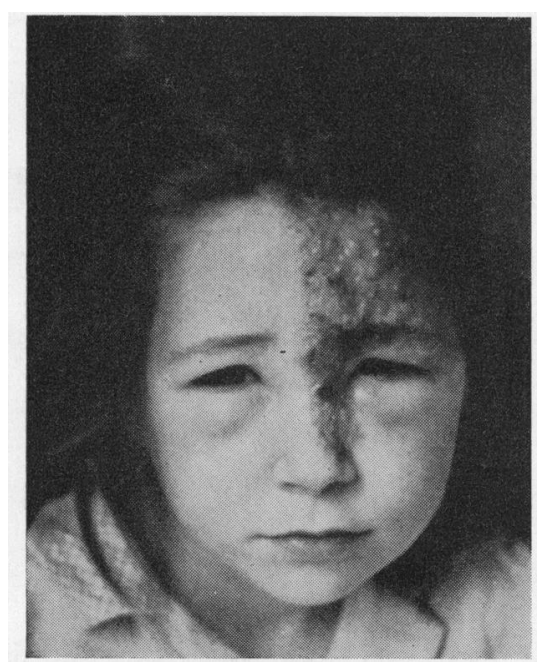

FIGURE.-Distribution of vesicular rash.

Laboratory Investigations. - The erythrocyte sedimentation rate was $6 \mathrm{~mm}$./hour; haemoglobin 78 per cent.; white blood cells 5,580 per cu. $\mathrm{cm}$., neutrophils 42 per cent., and lymphocytes 54 per cent.

* Received for publication March 26, 1962. 
Intranuclear inclusion bodies were found in the vesicular fluid on Giemsa staining.

Treatment.-Oc. Atropine 1 per cent. daily to the left eye and Cremor chloramphenicol twice daily to the vesicular rash.

Progress. - 2 days later the patient was pyrexial and the lower lids of both eyes became swollen. There was no neck rigidity and Kernig's sign was negative.

Oral penicillin V $125 \mathrm{mg}$. twice daily was given for 5 days at the onset of pyrexia.

The following day fever had subsided, and subsequently the swelling of the lids subsided, together with the vesicles. There was evidence of multifocal subepithelial keratitis of the left eye but none of anterior uveitis. The central nervous system was normal.

The patient was discharged from hospital on July 29, 1960.

Out-patient Treatment.-One tablet vitamin B complex twice daily and gutt. Eumydrine 1 per cent. to the left eye for one month.

Result.-The patient was finally discharged from the clinic on October 25,1960 . The corneal sensation was normal, and the cornea nearly clear. The anterior chamber, iris, and fundus were normal. The visual acuity was $6 / 6$. There were no subjective symptoms.

In January, 1961, the eye was white and the visual acuity 6/6. There were two small localized superficial corneal nebulae in the upper periphery. The anterior chamber was quiet, the ocular movements full, and the corneal sensation, pupil, and fundus were normal. The skin showed no macroscopic scars or anaesthetic areas.

\section{Discussion}

A review of the literature had indicated that 0.8 per cent. of cases of unilateral herpes zoster ophthalmicus occur between the ages of 6 and 13 years. The aetiology of most of these cases remains in doubt. The present case described had the features of the epidemic form of the disease.

Corneal involvement is the second commonest complication following herpes zoster ophthalmicus at all ages, occurring in 39 per cent. of cases. The case described had corneal involvement and eventually had two superficial localized corneal nebulae eccentrically placed as the only residual evidence of the disease. Subsequently corneal sensation returned to normal, and there was no scarring of the skin, and no paraesthesiae or neuralgia of the affected nerves.

Much clinical evidence has been presented to associate the herpes zoster virus with that of varicella and it is well known that adults may suffer from herpes zoster after attending children with varicella. Children have also suffered from varicella when they have been in contact with adults with herpes zoster. The two conditions rarely occur simultaneously.

The present case is of interest as the patient was a child who had not had chickenpox but was in quarantine for varicella from which some of her schoolmates were suffering.

I am grateful to Miss Mary Savory for kindly giving her permission to report the above case.

\section{REFERENCES}

Duke-ELDER, S. (1938). “Text-book of Ophthalmology", vol. 2, p. 1902. Kimpton, London. EDGerton, A. E. (1945). Arch. Ophthal. (Chicago), 34, 40. 